\title{
An initial exploration of the association between psychological distress and sedentary behaviour in first year undergraduates. A Practice Report
}

\author{
Charmaine Graham, Amanda Richardson, Sharron King, Belinda Chiera and Tim \\ Olds \\ University of South Australia, Adelaide, Australia
}

\begin{abstract}
University students are reported to have a higher prevalence of psychological distress than the general population. Consequently, research surrounding factors that may contribute to poor mental health of students is imperative in order to identify interventions for this at-risk population. Previous research has determined that sedentary behaviour is associated with physical health, with an emerging focus on the association between sedentary behaviour and mental health. As the role of student consists of primarily sedentary behaviours such as reading, writing and computer use, the relationship between these activities and student mental wellbeing is particularly relevant. The presentation reported on the findings of study conducted on a sample of first year undergraduates and their reported levels of psychological distress and use of time. The findings highlight the diverse and demanding lifestyles of today's student and the need for further research into student mental well-being.
\end{abstract}

Please cite this practice report as:

Graham, C., Richardson, A., King, S., Chiera, B \& Olds, T. (2014). An initial exploration of the association between psychological distress and sedentary behaviour in first year undergraduates. A Practice Report The International Journal of the First Year in Higher Education, 5(2), 95-101. doi: 10.5204/intjfyhe.v5i2.238

This practice report has been accepted for publication in Int J FYHE. Please see the Editorial Policies under the 'About' section of the Journal website for further information.

(C) Copyright of practice reports is retained by authors. As an open access journal, articles are free to use, with proper attribution, in educational and other non-commercial settings. ISSN: 1838-2959 


\section{Background}

A quarter of the Australian population are affected by psychological distress, with young adults (18-35) reported to experience the highest levels (Cvetkovski, Reavley, \& Jorm, 2012; Stallman, 2010). Psychological distress is composed of a number of mental health symptoms including low mood, anxiety or depression, and has been shown to have a negative correlation with psychological wellbeing (Winefield, 2009). Furthermore, psychological distress can be a precursor of more serious mental and physical health issues later in life (Hickie, 2011).

Research has shown a higher prevalence of psychological distress in Australian university students compared with the general population (Cvetkovski et al., 2012; Stallman, 2010). Despite distress occurring in both undergraduate and postgraduate students (Stallman, 2010), first year university students are considered to be particularly vulnerable due to the significant changes associated with the transition to university (McInnis, 2001).

The relationship between psychological distress and lifestyle is multifactorial and complex. However, recent research indicates an association between sedentary behaviour and poor psychological health. Sedentary behaviour (SB) is defined as any waking activity that involves sitting or reclining and has an energy expenditure < 1.5 metabolic equivalents (METS) (Sedentary Behaviour Research Network, 2013). An abundance of research exists investigating the association of sedentary behaviour and physical health, particularly diabetes (Grøntved \& Hu, 2011) and cardiovascular disease (Owen, 2012). However, fewer studies have been conducted to investigate the association between SB and mental health (Atkin, Bull,
\& Biddle, 2012; Kilpatrick, Sanderson, Blizzard, Teale, \& Venn, 2013; Sloan et al., 2013).

One of the earliest studies to focus on SB and mental health was conducted by Hamer and colleagues (Hamer, Stamatakis, \& Mishra, 2010) on a representative sample of Scottish adults. Study results found that high engagement time ( $>4 \mathrm{hrs} /$ day) in TV and screen-based entertainment (TVSE) was associated with poor mental health. However, no association was found for participants with low to moderate exposure to TVSE (up to $4 \mathrm{hrs} /$ day) (Hamer, Stamatakis, \& Mishra, 2010). Similar findings were reported in a UK study, with non-occupational sitting time-watching television, computer usage, socialising and commuting-found to have an adverse association with mental wellbeing in women, whereas only computer use had an adverse association with mental wellbeing for men (Atkin et al., 2012). In a combined study of men and women, Sloan and colleagues (Sloan et al., 2013) determined that high SB ( $>10$ hours per day) was associated with high psychological distress, independent of the SB activity. Furthermore, it was found that being active did not have an association with lower psychological distress, indicating that a person can meet the recommended daily physical activity levels but high levels of SB counteracts any mental health benefits achieved through activity (Sloan et al., 2013).

As a population whose "occupation" is primarily sedentary (Finlayson, Cecil, Higgs, Hill, \& Hetherington, 2012), university students are an important cohort to identify how sedentary lifestyle behaviours relate to their mental health. In a study of 3,367 public servants, Kilpatrick and colleagues (2013) found that employees primarily engaged in work that involved a longer time 
period ( $>$ 6hrs/day) of occupational sitting demonstrated moderate psychological distress for men, and moderate to high psychological distress for women. However no association was determined between occupational SB and very high psychological distress (Kilpatrick et al., 2013). Contrary to these findings, an earlier study on a sample of Dutch men found no association between occupational SB and mental health. However, a positive association was determined between recreational $\mathrm{SB}$, in particular $\mathrm{TV}$, and mental health (Proper, Picavet, Bemelmans, Verschuren, \& Wendel-Vos, 2012).

With the emerging research interest in recreational and occupational sedentary behaviour and mental health, the aim of the present study was to explore sedentary behaviours and psychological distress levels of a cohort of first year health science undergraduates.

\section{Method}

\section{Participants}

Participants consisted of 218 first year health science students, attending a metropolitan campus at the University of South Australia (UniSA). Age of the sample population was positively skewed $(M=18.8$ years, $S D=2.51$ ) with $95.3 \%$ of students aged between 18 and 24 years, and the majority (65.5\%) female.

\section{Measures}

Psychological distress was measured using the Kessler Psychological Distress Scale (K10 ), being a 10 -item scale that measures the level of distress experienced during the previous 30 days (Kessler et al., 2002). The scale consists of five response categories (1 $=$ none of the time to $5=$ all of the time) with total scores on the scale ranging from 10 to
50 (Kessler et al., 2002). Consistent with cut off points applied by the Australian Bureau of Statistics, scores were classified into four groups for analysis consisting of low distress (10-15), moderate distress (1621), high distress (22-29) and very high distress (30-50).

Sedentary behaviour was assessed using the Multimedia Activity Recall for Children and Adults (MARCA), an electronic 24h use of time recall that measures use of time and energy expenditure (Gomersall, Olds, \& Ridley, 2011). Participants recalled 1 to 2 days of activity, choosing from 600 different activities in time slices as fine as 5 minutes. Activities were classified into four categories based on energy expenditure, being sleep (0.9 METS); sedentary behaviour ( $<1.5 \mathrm{METS})$ such as study, and watching $\mathrm{TV}$; low physical activity (LPA)(1.6-2.9METS) including socialising, driving, and occupations such as checkout operator; moderate to vigorous physical activity (MVPA) ( $>$ 3.0METS) such as exercise, physically active chores, and occupations such as waitressing (Ainsworth et al., 2011). In instances where a participant recorded two days, time spent in each activity was averaged.

\section{Procedure}

As part of a broader project, the K10 and MARCA surveys received ethics approval from the UniSA's research ethic committee. The data were collected during second semester from a group of first year undergraduates attending a regular class. Students were informed that they would be de-identified and that participation was voluntary. 
Table 1: Mean time per day, per category, split by psychological distress levels

\begin{tabular}{lllll}
\hline & SB & LPA & MVPA & Sleep \\
\hline Low $(10-15)$ & $8.8 \mathrm{hrs}$ & $4.7 \mathrm{hrs}$ & $2.2 \mathrm{hrs}$ & $8.4 \mathrm{hrs}$ \\
Moderate $(16-21)$ & $8.2 \mathrm{hrs}$ & $5.0 \mathrm{hrs}$ & $2.1 \mathrm{hrs}$ & $8.7 \mathrm{hrs}$ \\
High $(22-29)$ & $8.7 \mathrm{hrs}$ & $4.6 \mathrm{hrs}$ & $1.8 \mathrm{hrs}$ & $9.0 \mathrm{hrs}$ \\
Very High $(30-50)$ & $9.1 \mathrm{hrs}$ & $4.9 \mathrm{hrs}$ & $1.9 \mathrm{hrs}$ & $8.2 \mathrm{hrs}$ \\
\hline Total & $8.7 \mathrm{hrs}$ & $4.8 \mathrm{hrs}$ & $2.0 \mathrm{hrs}$ & $8.6 \mathrm{hrs}$ \\
\hline
\end{tabular}

\section{Results and Discussion}

Overall, $80.4 \%$ of students $(n=174)$ reported elevated scores on the K10 $(M=21.21, S D=6.63)$, with $20.5 \% \quad(n=45)$ reporting low levels of psychological distress (10-15). A total of $38.8 \%$ of students $(n=85)$ reported scores between 16-21 indicating moderate psychological distress; $26.5 \%(n=58)$ reported scores of 22-29 indicating high psychological distress; and $14.2 \%(n=31)$ reported scores between 30-50 indicating serious very high psychological distress. A series of Mann Whitney analyses indicated no significant differences between student level of distress based on age or gender.

In regards to use of time, students displayed a similar pattern of average energy expenditure across all psychological distress levels. Table 1 presents the average amount of time spent per day across four categories of activities split by psychological distress levels.

A multinominal regression analysis was conducted to determine whether any categories of energy expenditure related to levels of psychological distress. However the model only explained 5\% (Cox and Snell R Square; Nagelkereke R Square) of the variance in psychological distress. Table 2 presents the results indicating that no association was found between SB and the four levels of psychological distress, however a weak negative association was found between MVPA and high psychological distress.

In examining the results a key distinguishing feature should be highlighted. Participants involved in this study were in a much lower age range $(M=$ 18.8 years) when compared with other studies in this field, such as Atkin et al. (2012) ( $M=40.4$ years), Kilpatrick et al. (2013) ( $M=46.2$ years) and Sloan et al. (2013) ( $M=43 y e a r s)$. Consequently the association between SB and psychological distress may vary across different age ranges. This variation may be a result of differing behaviours and motivations, supporting Atkin et al.'s recommendation that individual SB activities should be assessed in context with behaviours and motivations, as opposed to duration of time performing SB activities.

There are a number of limitations of this study that should be highlighted. Firstly, the use of time data relied on student recall of the previous day/s activities, resulting in potential reliability issues. Secondly, the sample was made up of a cohort of students studying health science which as a result may contribute towards healthier lifestyle behaviours when compared with broader university samples. Furthermore, data was

98 | The International J ournal of the First Year in Higher Education, 5(2) August, 2014 


\begin{tabular}{|c|c|c|c|c|c|c|c|}
\hline \multirow[b]{2}{*}{ PD Level } & \multirow[b]{2}{*}{$B(\mathrm{SE})$} & \multirow[b]{2}{*}{ Wald } & \multirow[b]{2}{*}{ df } & \multirow[b]{2}{*}{$p$} & \multicolumn{2}{|c|}{ 95\% Cl for Odds Ratio } & \multirow[b]{2}{*}{ Upper } \\
\hline & & & & & Odds & Lower & \\
\hline \multicolumn{8}{|l|}{ Moderate } \\
\hline Intercept & $3.048(2.03)$ & 2.25 & 1 & .134 & & & \\
\hline SB & $-.003(.002)$ & 1.93 & 1 & .164 & .997 & .992 & 1.001 \\
\hline LPA & $-.001(.003)$ & .286 & 1 & .593 & .999 & .994 & 1.004 \\
\hline MVPA & $-.003(.003)$ & 1.219 & 1 & .270 & .997 & .992 & 1.002 \\
\hline \multicolumn{8}{|l|}{ High } \\
\hline Intercept & $4.319(2.18)$ & 3.923 & 1 & .048 & & & \\
\hline SB & $-.004(.002)$ & 2.718 & 1 & .099 & .996 & .991 & 1.001 \\
\hline LPA & $-.004(.003)$ & 2.136 & 1 & .144 & .993 & .991 & 1.001 \\
\hline MVPA & $-.007(.003)$ & 5.028 & 1 & .025 & .993 & .987 & .999 \\
\hline \multicolumn{8}{|l|}{ Very High } \\
\hline Intercept & $-1.424(2.49)$ & .327 & 1 & .567 & & & \\
\hline SB & $.001(.003)$ & .310 & 1 & .578 & 1.001 & .996 & 1.007 \\
\hline LPA & $.002(.003)$ & .379 & 1 & .538 & 1.002 & .996 & 1.008 \\
\hline MVPA & $-.001(.003)$ & .138 & 1 & .710 & .999 & .992 & 1.005 \\
\hline
\end{tabular}

gathered in the second semester of university, with students found to have elevated psychological distress levels in second semester compared with first semester (Cvetkovski et al., 2012; Stallman, 2010). Consequently increased academic stress may have had a confounding effect, which was not controlled for in this study. As a result, further research is necessary to determine whether an association between SB and psychological distress exists for students studying programs that do not have a health science focus, and that controls for existing academic stress.

In conclusion, the present study explored the association between sedentary behaviour and psychological distress in a cohort of first year health science undergraduates. This is the first study that we are aware of that has focused on sedentary behaviour in a student population, and it has highlighted the potential difference that the association between SB and psychological distress has in different cohorts. Recommendations of future research include a focus on specific cohorts which should provide further insight into the variability amongst groups and any association between SB and psychological distress.

\section{Overview of conference feedback}

Discussion by delegates at the $201417^{\text {th }}$ International First Year in Higher Education Conference in Darwin, Australia, reinforced the multifactorial and complex nature of psychological distress and lifestyle, identifying additional key factors as:

- resilience

- $\quad$ sense of belonging

- $\quad$ academic stress points

- exacerbation of pre-existing psychological distress

- non-acceptance into first course preferences

- $\quad$ external commitments including part time employment 
Overall, delegates provided positive feedback, demonstrating an interest in further examination of the association between student psychological distress and sedentary behaviour. In particular, interest was expressed in further exploration of a larger data sample that would enable a comprehensive analysis of individual activities engaged in by students, and the investigation of potential gender differences.

The conference outcomes highlighted that student psychological wellbeing remains a key concern for higher education. This focus indicates the importance of the continuation of higher education research into different aspects of student life, in an attempt to further understand and where possible improve student mental wellbeing.

\section{References}

Ainsworth, B., Haskell, W., Herrmann, S., Meckes, N., Bassett, D., Tudor-Locke, C., \&Leon, A. (2011). 2011 compendium of physical activities: A second update of codes and MET values. Medicine and Science in Sports and Exercise, 43(8), 1575-1581.

Atkin, A., Bull, F., \& Biddle, S. (2012). Non-occupational sitting and mental well-being in employed adults. Annals of behavioral medicine, 43(2), 181188. doi: 10.1007/s12160-011-9320-y.

Cvetkovski, S., Reavley, N., \& Jorm, A. (2012). The prevalence and correlates of psychological distress in Australian tertiary students compared to their community peers. Australian and New Zealand Journal of Psychiatry, 46(5), 457-467. doi: 10.1177/0004867411435290

Finlayson, G., Cecil, J., Higgs, S., Hill, A., \& Hetherington, M. (2012). Susceptibility to weight gain. Eating behaviour traits and physical activity as predictors of weight gain during the first year of university. Appetite, 58(3), 1091-1098. doi: 10.1016/j.appet.2012.03.003

Gomersall, S., Olds, T., \& Ridley, K. (2011). Development and evaluation of an adult use-oftime instrument with an energy expenditure focus. Journal of Science and Medicine in Sport,
$14(2)$

143-148.

10.1016/j.jsams.2010.08.006

doi:

Grøntved, A., \& Hu, F. (2011). Television viewing and risk of type 2 diabetes, cardiovascular disease, and all-cause mortality. JAMA: The Journal of the American Medical Association, 305(23), 24482485. doi: 10.1001/jama.2011.812

Hamer, M., Stamatakis, E., \& Mishra, G. D. (2010). Television- and screen-based activity and mental well-being in adults. American Journal of Preventive Medicine, 38(4), 375-380. doi: 10.1016/j.amepre.2009.12.030

Hickie, I. (2011). Youth mental health: We know where we are and we can now say where we need to go next. Early intervention in psychiatry, 5(s1), 6369. doi: 10.1111/j.1751-7893.2010.00243.x

Kessler, R., Andrews, G., Colpe, L., Hiripi, E., Mroczek, D., Normand, S. \& Zaslavsky, A. (2002). Short screening scales to monitor population prevalences and trends in non-specific psychological distress. Psychological medicine, 32(6), 959-976.

Kilpatrick, M., Sanderson, K., Blizzard, L., Teale, B., \& Venn, A. (2013). Cross-sectional associations between sitting at work and psychological distress: Reducing sitting time may benefit mental health. Mental Health and Physical Activity, 6(2), 103-109. doi: 10.1016/j.mhpa.2013.06.004

McInnis, C. (2001). Researching the first year experience: Where to from here? Higher Education Research and Development, 20(2), 105-114.

Owen, N. (2012). Ambulatory monitoring and sedentary behaviour: A population-health perspective. Physiological measurement, 33(11), 1801.

Proper, K., Picavet, H., Bemelmans, W., Verschuren, W., \& Wendel-Vos, G. (2012). Sitting behaviors and mental health among workers and nonworkers: The role of weight status. Journal of Obesity, 2012. Article ID 60798, 9 pages. doi: $10.1155 / 2012 / 607908$

Sedentary Behaviour Research Network. (2013). Letter to the Editor. Standardized use of the terms "sedentary" and "sedentary behaviours". Mental Health and Physical Activity, 6(1), 55-56.

Sloan, R., Sawada, S., Girdano, D., Liu, Y., Biddle, S., \& Blair, S. (2013). Associations of sedentary behavior and physical activity with psychological distress: A cross-sectional study from Singapore. BMC public health, 13(1), 885. doi: 10.1186/1471-2458-13-885 
Stallman, H. (2010). Psychological distress in university students: A comparison with general population data. Australian Psychologist, 45(4), 249-257. doi: 10.1080/00050067.2010.482109

Winefield, H., Taylor, A, Gill, T, Pilkington, R, Koster, C. (2009). The relationship between psychological distress and psychological wellbeing. A report prepared for The Assessment of the Determinants and Epidemiology of Psychological Distress (ADEPD) Study. Discipline of Psychiatry, University of Adelaide. Retrieved from http://www.health.sa.gov.au/pros/portals/0/A DEPD Psychological Distress and wellbeing final report.pdf 